\title{
$\underline{\text { A Content Analysis of Peer Feedback in Triadic Supervision }}$
}

By: Janeé R. Avent, Edward Wahesh, Lucy L. Purgason, L. DiAnne Borders and A. Keith Mobley

This is the peer reviewed version of the following article:

Avent, J. A., Wahesh, E., Purgason, L. L., Borders, L. D., \& Mobley, A. K. (2015). Content analysis of peer feedback in triadic supervision. Counselor Education and Supervision, $54,68-80$.

which has been published in final form at http://dx.doi.org/10.1002/j.15566978.2015.00071.x This article may be used for non-commercial purposes in accordance with Wiley Terms and Conditions for Self-Archiving.

\section{Abstract:}

There is limited research on the types of peer feedback exchanged during triadic supervision. Through a content analysis, the authors found that students provided feedback about counseling performance and cognitive counseling skills most often in supervision sessions. However, there were differences in the types of feedback exchanged across three experience levels.

Keywords: supervision | triadic supervision | peer feedback

\section{Article:}

Clinical supervision has been described as both a fundamental intervention and an instrumental pedagogy in counselor education (Bernard \& Goodyear, 2014). Historically, supervisors provided supervision through individual and group sessions, but, in 2001, the Council for Accreditation of Counseling and Related Educational Programs (CACREP, 2001) introduced triadic supervision, a "tutorial and mentoring relationship" (p. 64) between one supervisor and two supervisees who meet simultaneously, as a substitute for individual sessions. Since then, with continued CACREP (2009) endorsement of the triadic modality, a number of supervisors have opted for triadic rather than individual sessions (Lawson, Hein, \& Getz, 2009). Their approaches to triadic sessions are typically either single focused, focusing on one supervisee each week, or split focused, dividing the time equally between both supervisees each week (Lawson, Hein, \& Getz, 2009).

Subsequent research, however, has revealed a more nuanced view of the pedagogy of triadic supervision from both the supervisors' and supervisees' perspectives. Researchers (e.g., Borders et al., 2012; Hein \& Lawson, 2008, 2009; Hein, Lawson, \& Rodriguez, 2011, 2013; Lawson, Hein, \& Stuart, 2009, 2010; Stinchfield, Hill, \& Kleist, 2010) have identified the benefits and challenges of triadic supervision, many of which revolve around peer feedback. Across all these studies, both supervisors and supervisees reported that they valued the vicarious learning opportunities and multiple, diverse perspectives that are possible when receiving both supervisor and supervisee feedback. In fact, supervisees sometimes received peer feedback more easily or 
understood peer feedback better than supervisor feedback (Borders et al., 2012; Lawson et al., 2010). On the other hand, supervisees also reported sometimes feeling awkward about providing feedback to their peers and were reluctant to give critical feedback (Hein \& Lawson, 2008; Lawson, Hein, \& Getz, 2009). In addition, when supervisees reported being in mismatched pairings, based on differing counseling skill levels, personality, or developmental levels, both supervisees and supervisors said the peer feedback was not helpful (Borders et al., 2012; Hein \& Lawson, 2008, 2009; Hein et al., 2011, 2013; Lawson, Hein, \& Getz, 2009). Thus, although peer feedback is highly valued, it appears that supervisors need to assist supervisees in providing appropriate feedback if supervisees are to achieve the potential advantages of triadic supervision.

Although identification of beneficial and challenging aspects of peer feedback is certainly instructive, these descriptions provide limited insights into the feedback that supervisees find helpful in triadic supervision or even the type of feedback that they are capable of giving. For example, supervisees might vary based on their ability to give feedback about their peer's counseling skills, case conceptualization, or self-awareness, which are the key supervision focus areas specified in Bernard's (1997) Discrimination Model. Although all three areas are important to counselor change and growth, supervisees' attention to these focus areas in their peer feedback might be expected to vary based on their developmental level (Borders \& Brown, 2005; Stoltenberg \& McNeill, 1997). Supervisees in the early stages of development (e.g., practicum) tend to focus primarily on skill development and thus could be expected to give more attention to a peer's use of counseling skills during a counseling session. Supervisees in the middle developmental stage have acquired enough proficiency in their skills to broaden their focus to case conceptualization. They are ready to use the information gained from the client (through use of their skills) to construct a comprehensive understanding of the client (e.g., underlying client dynamics, past and present influences on client's behaviors, implications for supervisees' work with the client). Thus, supervisees might be expected to give more attention to case conceptualization in their peer feedback. During later developmental stages, supervisees have acquired counseling and conceptualization skills for deeper work with clients, which often illuminate self-awareness issues, including transference and countertransference. Supervisees at this stage are more confident and open to exploring such issues. As a result, they might be expected to include more self-awareness feedback to their peers during triadic supervision.

Although counselor developmental level involves more than experience level (e.g., cognitive complexity), researchers often have used experience levels (e.g., practicum, first and second internship) as a proxy for developmental level and found that differences by experience level do reflect descriptions of early, middle, and later developmental levels (e.g., Bernard \& Goodyear, 2014; Goodyear \& Guzzardo, 2000). Knowledge about potential developmental variations in the types of feedback provided by peers would provide initial information for supervisors facilitating triadic supervision, suggesting which areas supervisees at each experience level tend to emphasize in peer feedback and which they may need encouragement, or even instruction, to consider.

Thus, the purpose of this study was to provide initial, baseline data on the types of feedback provided by supervisees at three experience levels during triadic supervision sessions. Two research questions guided the study: (a) What types of feedback do peers provide during triadic 
supervision, and at what frequency? (b) What are the differences in types of peer feedback delivered by practicum students, first-semester interns, and second-semester interns?

\section{Method}

We viewed triadic supervision sessions $(\mathrm{N}=15)$ previously recorded as part of a larger study of counseling and supervision in a counseling training clinic and analyzed them using content analysis. Supervisees were enrolled in an entry-level counseling program participating in a practicum or internship; supervisors were doctoral students completing a supervised supervision internship. All sessions were recorded in the counseling training clinic between 2011 and 2013. The recordings, stored in a secure electronic database, were available under existing approval from the local university's institutional review board.

\section{Participants}

All participants were enrolled in a CACREP-approved counseling program in the southeastern United States. The supervisors included 10 students (i.e., two African American women, five European American women, and three European American men) enrolled in the counselor education doctoral program. All had completed a didactic supervision course and were receiving supervision of supervision by a program faculty member. Supervisees included 11 students enrolled in practicum, 12 students enrolled in their first semester of internship, and six students enrolled in their second semester of internship. The supervisees included two African American men, three African American women, 22 European American women, two European American men, and one Asian American man; one supervisee in practicum appeared in more than one recording. The supervisees included students from clinical mental health, school counseling, couple and family counseling, and college counseling/student development programs. Supervisee pairings for the triadic sessions included three female-female pairs and three female-male pairs for practicum, five female-female pairs and one male-female pair for the first-semester internship, and two female-female pairs and one female-male pair for the second-semester internship.

\section{Procedure}

We used content analysis because of its ability to increase insight and inform practical implications for novel phenomena (Krippendorff, 2012), such as triadic supervision. Krippendorff (2012) defined content analysis as "a research technique for making replicable and valid inferences from texts (or other meaningful matter) to the contexts of their use" (p. 24). This methodology can align as either more quantitative or more qualitative. We followed Insch, Moore, and Murphy's (1997) guidelines for conducting content analysis, as outlined in Hays and Singh (2012), which include identifying the texts to be examined, specifying the units of analysis and categories, conducting a pretest to purify the coding scheme, collecting data, and assessing reliability and validity before analyzing the data.

According to Krippendorff (2012), texts are not limited to written content but can include visual content, such as videotapes. Thus, we viewed recorded triadic supervision sessions to analyze feedback statements. As part of the triadic supervision process, supervisees viewed each other's 
counseling session before the supervision session and exchanged feedback during the triadic session by using a worksheet provided by the supervisor. The worksheet comprised several prompts to allow the supervisees to assess their peers' strengths and areas for improvement, offer suggestions, identify what they learned from watching the recording, and consider how they might apply what they learned in their own counseling practices (Borders, Brown, \& Lewis, 2014). The supervisor also watched both of the supervisees' recordings in advance and, during supervision, facilitated discussion between the peer supervisees. We did not include the worksheets in the coding process.

Data analysis. The specific unit of analysis was defined as an uninterrupted speaking turn in which a peer (supervisee) provided feedback to a peer (supervisee) during the triadic supervision session. Units of analysis were assigned to a priori categories based on Bernard's (1997) Discrimination Model, as adapted by Borders and Brown (2005), and included (a) counselor performance skills, (b) cognitive counseling skills, (c) self-awareness, and (d) professional behaviors. We also included a category entitled other that allowed for open coding for any peer feedback statements that did not meet the definition for the aforementioned categories.

For the pretest, the coding team (i.e., the first three authors), analyzed three randomly selected triadic supervision sessions, one each from practicum, first-semester internship, and secondsemester internship, to test the coding scheme and assess construct validity. Each coding team member independently viewed and coded the three sessions and then met to view the recordings and codings together. As a result, the coding team refined the definitions to improve the discriminant validity of the categories and minimize ambiguity in coding (Stemler, 2001).

To aid in the coding process, we created a codebook with an operationalized definition of each category. The counseling performance skills category was operationalized as feedback related to skills and interventions observed in the counseling session. The cognitive counseling skills category was defined as feedback related to the conceptualization of the client or therapeutic relationship. Feedback related to the supervisee's role in the therapeutic relationship, including comments about countertransference, comprised the self-awareness category. We defined the professional behaviors category as feedback related to ethical and legal issues that arise in counseling.

According to Neuendorf (2002), a minimum of 384 units is necessary to generalize the results of a content analysis with a $95 \%$ level of confidence. Furthermore, we calculated that to examine group differences in feedback (Research Question 2), an estimated 495 units were necessary to satisfy an assumption of the Chi-square test of independence related to minimum cell size (i.e., no more than $20 \%$ of the expected cell counts or fewer than 5; Field, 2013). Based on the average number of units per recording observed during the pretest $(\mathrm{M}=32.50 ; \mathrm{SD}=11.74)$, we calculated that five recordings per group (15 total) were necessary to ensure that we met these criteria.

We also decided to include only recordings of triadic supervision sessions that occurred postmidterm. We excluded pre-midterm supervision sessions to minimize confounding variables that could exist from including sessions from various times in the semester. We expected that the quality of the supevisees' feedback would develop and stabilize after several weeks of interaction 
with their peers and supervisors. Only three recordings of triadic supervision with secondsemester interns met this criterion. Thus, we included all of these sessions in our study. Using a random number generation, we randomly selected six recordings of triadic supervision with firstsemester interns and six recordings of practicum supervisees from the remaining pool of supervision recordings to reach our goal of analyzing 15 recordings.

To increase stability and reproducibility, each session was coded independently by two raters (i.e., from the first three authors; Stemler, 2001). After we had coded all of the sessions, the first author merged the independent coding files and reviewed all coding to identify any discrepancies in the total number of units found in each session. To resolve conflicts in the number of units identified, a third rater (i.e., one of the first three authors who did not conduct the initial coding) served as an auditor to review and reconcile any differences in the total number of units found by the original two raters. After we resolved these discrepancies, we assessed reliability. There was $82 \%$ agreement in coding and interrater reliability (Cohen's kappa $=.72$ ), indicating substantial consensus among raters (Landis \& Koch, 1977). The high level of agreement among raters provided evidence for discriminant validity of the five feedback categories. Because we wished to compare the frequency of peer feedback by discrete groups (Research Question 2), we used the "odd-man-out" (p. 15) process recommended by Insch et al. (1997) to reconcile coding differences among raters and ensure that all observed units were assigned to a single category.

The category with the highest percentage of disagreement among raters (33\%) was selfawareness. In most cases, raters disagreed about whether to classify these units in the selfawareness feedback or other category. After reviewing these categories and units, we retitled the other category as self-reflection because these units captured feedback based on the supervisee's own personal self-reflections. Whereas self-awareness was defined as feedback pertaining to issues such as countertransference in the therapeutic relationship, the self-reflection category encompassed statements that represented increased self-awareness by the peer after viewing or discussing the supervisee's counseling session.

We used descriptive statistics (i.e., counts, frequencies) and comments that were representative examples of each category to investigate Research Question 1. For Research Question 2, we used a Chi-square analysis to determine whether significant differences existed in the frequency of feedback categories across the three groups (i.e., practicum students, first-semester interns, second-semester interns). To identify which cells within the contingency table provided the most contribution to the Chi-square, we computed adjusted standardized residuals. Adjusted standardized residuals are similar to z scores in that they are normally distributed with a mean of zero and a standard deviation of one (Agresti, 2010). Thus, if an adjusted standardized residual has an absolute value greater than or equal to 1.96 (i.e., z score associated with a .05 alpha level), it can be determined that the observed frequency is significantly different from the expected frequency. Cramer's V was also calculated to determine effect size.

\section{Results}

The content analysis yielded 581 total units of peer feedback across the 15 recorded triadic supervision sessions. The mean number of units per session was 39 (SD =21.14), with a range of 15 to 98 units observed. Frequencies of each category are displayed in Table 1. The category of feedback most commonly delivered overall during triadic supervision was cognitive counseling 
skills ( $\mathrm{n}=283,49 \%)$. Cognitive counseling skills feedback included references to case conceptualization and the use of theory in counseling: "I am also kind of wondering if she is coming to you telling you this just trying to get a reaction from you since she can't get a reaction from anyone else" and "Just because it seemed like maybe solution focused - if you really wanted to get some kind of consensus of how can we do this and maybe work backwards from there."

Table 1. Peer Feedback Category Frequency Counts and Adjusted Standardized Residuals (ASRs) by Experience Level

\begin{tabular}{|c|c|c|c|c|c|c|}
\hline \multirow[b]{3}{*}{ Peer Feedback Category } & \multicolumn{6}{|c|}{ Supervisee Group } \\
\hline & \multicolumn{2}{|c|}{ Practicum $(N=211)$} & \multicolumn{2}{|c|}{ First-Semester Internship $(N=222)$} & \multicolumn{2}{|c|}{ Second-Semester Internship $(N=148$} \\
\hline & $n$ & ASR & $n$ & ASR & $n$ & ASR \\
\hline Counseling performance skills & 87 & 2.4 & 60 & -3.1 & 56 & 0.9 \\
\hline Cognitive counseling skills & 92 & -1.9 & 127 & 3.2 & 64 & -1.5 \\
\hline Self-awareness & 17 & -0.5 & 24 & 1.4 & 10 & -1.0 \\
\hline Professional behaviors & 9 & -0.3 & 7 & -1.3 & 11 & 1.9 \\
\hline Self-reflection & 6 & -0.1 & 4 & -1.3 & 7 & 1.5 \\
\hline
\end{tabular}

The counseling performance skills category $(n=203,35 \%)$ was the second most frequently shared type of feedback observed. This category included feedback on the use of specific skills used by the counselor. In one supervision session, a supervisee noted her peer's pacing skills:

I felt like in the beginning it was a little rushed. I can always tell on your tape in the beginning your voice is higher pitched. By minute 10, you were catching your groove. You were calm. But, definitely, in the first part, I felt it was question after question after question.

Similarly, a supervisee commented on her peer's use of reframing in the session: "I heard good summarizations and reframing. I think they said something about behaviors, and you really reframed it as more caring."

The self-awareness $(n=51,9 \%)$ and professional behaviors $(n=27,5 \%)$ categories were less frequently observed. Self-awareness feedback included comments made by the peer about possible personal issues that might have influenced the counselor's clinical work. For example, a student stated to her peer, "Ok, well um, I want to hit on a word that you said-reparative session - reparative for you or for her?" Professional behaviors feedback included ethical and legal issues within the counseling relationship and supervision behaviors. For example, a student commented on her peer's suicide assessment: "being direct about if you do feel like someone might kill themselves. You can be more clear about what you're dealing with." Similarly, a counselor provided feedback to her peer on how to broach the issue of child abuse in the session: "I think mom mentioned spanking at some point in there in regard to the incident, and I thinkone, that is just a straight-up opening."

Self-reflection, a category that emerged during data analysis, was the least frequently observed type of feedback $(n=17,3 \%)$. Self-reflection statements were made by peers about their 
experience while reviewing the counselor's work or when discussing their peer's performance. For example, one practicum supervisee commented, "I really liked your approach 'What's helped you get through the difficult times?' I don't know if I would have thought of that or worded it that way." In some cases, self-reflection feedback included comments made by students about how they had learned something from watching their peers (e.g., "My style is more passive. I'm wanting to draw from you but then if I'm getting regurgitation, it would be helpful to have the skill of narrowing and focusing and that's what I put in my toolbox here.").

To answer the second research question, we subdivided the feedback categories by supervision experience level (i.e., practicum, first-semester internship, second-semester internship) and calculated frequencies by category and level. Cognitive counseling skills was the most common category among supervisees across all three experience levels, followed by counseling performance skills (see Figure 1). First-semester interns provided the highest percentage of selfawareness feedback (47\%), followed by practicum (33\%) and second-semester internship (20\%). Conversely, second-semester interns had the highest frequency of feedback regarding professional behaviors (41\%), followed by practicum students (33\%) and first-semester interns (26\%). The category with the fewest units was self-reflection; second-semester interns provided the highest percentage of this feedback $(41 \%)$, followed by practicum students $(35 \%)$ and firstsemester interns $(24 \%)$.

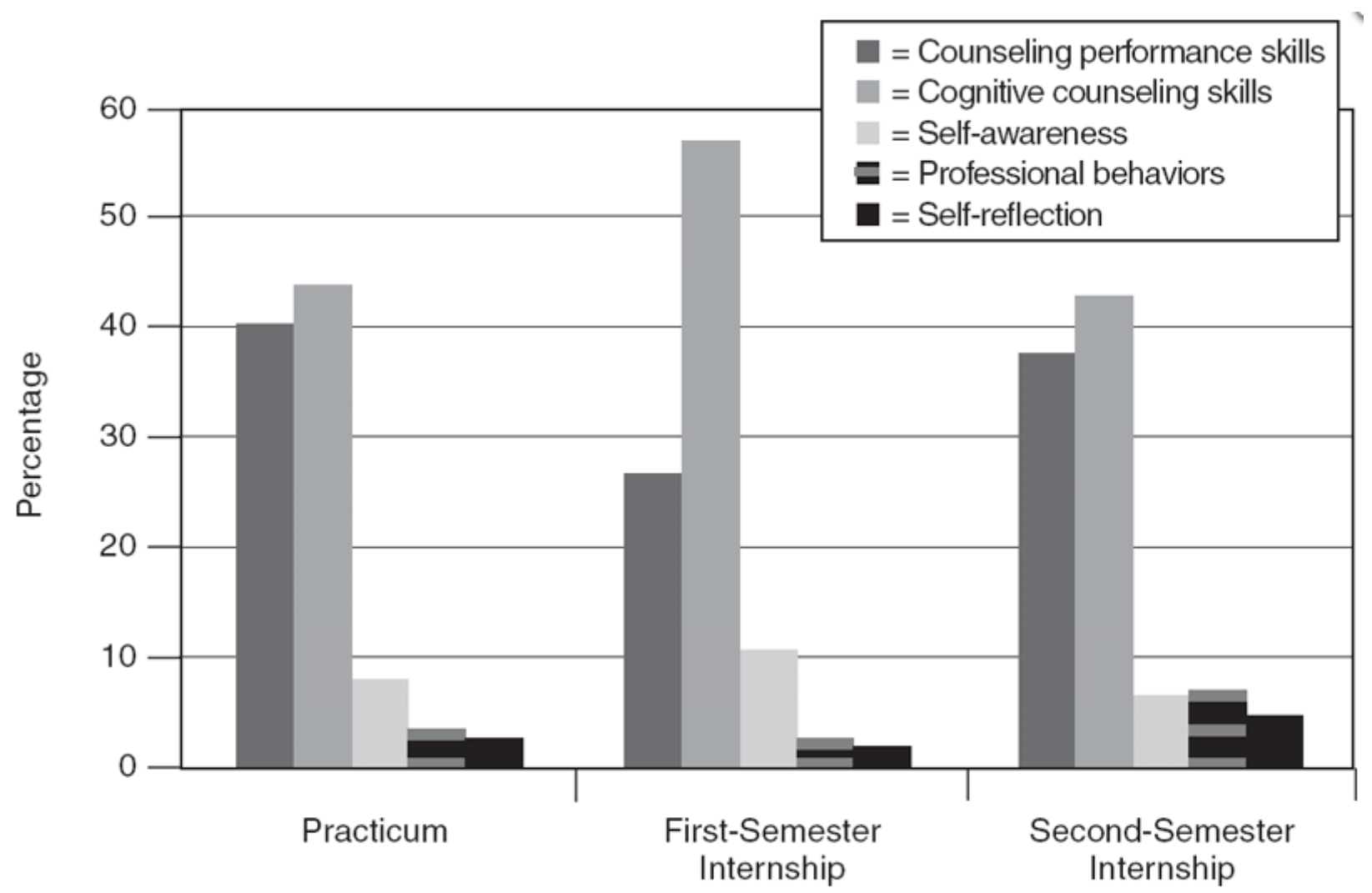

Figure 1. Frequency of Peer Feedback Categories by Experience Level

Chi-square analysis revealed that the relationship between the five peer feedback categories and three supervision groups was significant, $\chi 2(8, \mathrm{~N}=581)=20.2, \mathrm{p}<.01$ (see Table 1 ). The effect 
size for this analysis (Cramer's $V=.13$ ) was between Cohen's (1988) convention for a small (.10) and medium effect (.15). Counseling performance skills feedback by practicum students (2.4) and cognitive counseling skills feedback by first-semester interns (3.2) had adjusted standardized residuals greater than 1.96, indicating that the number of cases in these cells was significantly larger than would be expected if the hypothesis of independence was true. Furthermore, counseling performance skills feedback by first-semester interns (-3.1) had an adjusted standardized residual less than -1.96 ; therefore, this group provided fewer units of feedback in this category than was expected. First-semester interns had a greater frequency of self-awareness feedback than practicum students; however, the adjusted standardized residual was below 1.96, indicating that this cell did not make a significant $(\mathrm{p}<.05)$ contribution to the Chi-square.

\section{Discussion}

To capitalize on the learning outcomes of triadic supervision, supervisors must know more about the types of peer feedback exchanged and how this feedback varies across the experience level of counseling trainees. Results from our study provide initial evidence of the types of feedback generated by peers during triadic supervision across three experience levels: practicum, firstsemester internship, and second-semester internship. Furthermore, differences existed across experience levels with regard to the type of feedback shared in triadic supervision, reflecting characteristics of their different developmental levels (Borders \& Brown, 2005; Stoltenberg \& McNeill, 1997).

For example, students in their practicum experience were more likely to share feedback with their peers related to counseling performance skills observed in the session, which was in line with their developmental focus on skill development. Conversely, students participating in their first semester of internship exchanged a significantly larger amount of feedback related to case conceptualization and other cognitive counseling considerations. Higher incidences of cognitive counseling skills feedback by first-semester interns over practicum and second-semester interns reflects the developmental shift that occurs as students move from practicum into internship. Developmentally, first-semester interns are moving away from the self-focus of skill application to the client focus of case conceptualization (Stoltenberg \& McNeill, 1997). Second-semester interns, on the other hand, are dealing with the impending professional identity transition from counselor trainee to professional counselor. Supervision goals involve cultivating autonomy and encouraging self-monitoring regarding professional behaviors and practice. Therefore, it is not surprising that second-semester interns provided the highest levels of feedback related to professional behaviors and self-reflection. Thus, counselor development models provide an explanation for several differences in peer feedback across supervisees' experience levels.

Even though self-reflection feedback was more likely to occur with second-semester interns, the rates did not differ significantly across experience levels. Self-reflection feedback involved a peer specifically commenting about how their learning was affected by observing their peer's counseling work. This vicarious learning opportunity has been cited as a benefit of triadic supervision by both practicum- and internship-level supervisees and may be both a unique opportunity and an advantage of triadic sessions if emphasized by the supervisor (Borders et al., 2012; Lawson, Hein, \& Getz, 2009; Stinchfield et al., 2010). 
Although the findings are preliminary, the significant differences in rates of cognitive counseling and performance skills over other types of feedback indicate that triadic supervision may be an effective modality for facilitating the exchange of these types of feedback among peers. Conversely, using triadic supervision as a way to facilitate feedback related to professional behaviors and self-awareness may require additional intentionality on the part of the supervisor and consideration of why supervisees may be reluctant to address these areas. There are at least several reasons why feedback related to self-awareness and professional behaviors may occur less frequently in triadic sessions. Sharing feedback related to self-awareness constructs involves a supervisee commenting on a peer's personal issues that might be affecting the counseling relationship. This deeper level of feedback necessitates a greater amount of trust on the part of the supervisees and requires the supervisees to have a deeper understanding of their peers, including personal experiences, theoretical orientation, and supervision goals.

Borders et al. (2012) found that supervisees consistently cited individual supervision (vs. triadic and group supervision) as a modality that facilitated greater levels of self-awareness and personal growth and was deeper and more challenging. Supervisees said they were hesitant to share feedback with peers that could be viewed as potentially negative and said skills mismatches also contributed to feeling less safe about sharing feedback in that modality (Borders et al., 2012). As a way to address these concerns, Stinchfield, Hill, and Kleist (2007) recommended that peers be matched based on a pre-established positive relationship. The results from our study suggest that, when using triadic supervision as a modality, supervisors may also want to select peers by considering issues such as the following: (a) "Is there a specific feedback area that this supervisee needs?" (b) "How can I facilitate the exchange of this feedback during triadic supervision?" and (c) "How could feedback from a peer help facilitate any developmental transition areas?"

Researchers (Borders et al., 2012; Lawson et al., 2010) consistently have indicated that the structure and instruction of triadic supervision should be intentionally fashioned based on the supervisor's desired outcomes. In addition, Borders et al. (2012) concluded that supervisees need "instruction regarding expectations for their contributions to the triadic process, as peers can be both an asset and a barrier to feedback during triadic sessions" (p. 294). Thus, an important consideration involves the supervisor providing a structured feedback worksheet for supervisees to use when viewing their peer's counseling sessions (Borders et al., 2014). As mentioned earlier, most of the supervisors in our project requested that supervisees watch their peer's counseling session in its entirety and respond to some questions about the session before the triadic supervision session. Considering the aforementioned findings, supervisors may need to provide questions on this worksheet that facilitate feedback related to counseling performance skills, cognitive counseling skills, self-awareness, professional behavior, and self-reflection, and should be prepared to facilitate dialogue on each area during the session. Additionally, it may be important for supervisees to be told in advance of the expectations of their role during triadic supervision, specifically the types of feedback that should be shared with peers. Examples of prompts that supervisors could use with supervisees to promote self-awareness include "As you listened to your peer's feedback, is there anything that surprises you about what he or she said?" or "What do you make of your peer's feedback in light of how you viewed the session?" Supervisors could elicit feedback related to professional behaviors with questions such as (a) 
"What are some ethical concerns/issues that may arise with this client/presenting concern?" (b) "How would you know if you needed to consult?" or (c) "What risk factors are present?" To facilitate self-reflection, supervisors could include prompts such as, "What did you learn from your peer's session that could be helpful to your own work?" or "What did you learn about yourself from watching your peer interact with her client?” (Borders et al., 2014).

There are some important implications that exist for programs regarding choosing a standard triadic supervision model to use throughout the curriculum. An advantage of choosing a standard model is that it allows for consistent expectations for triadic supervision across counselor trainee experience level. Currently, few tested models for triadic supervision exist. Considering our results, an important area to address in selecting or implementing a triadic model would be one that would facilitate the exchange of feedback across each of the five content areas: counseling performance skills, cognitive counseling skills, self-awareness, professional behaviors, and selfreflection. The Reflective Model of Triadic Supervision (Stinchfield et al., 2007) shows promise for the ability to help peer supervisees in triadic sessions give feedback to each other related to case conceptualization, performance skills, and the ability to connect what they observed their peers doing with their own counseling work. However, the model does not specifically address how to facilitate feedback around professional behaviors, self-awareness, or self-reflection categories, such as those provided in Borders et al. (2014).

\section{Limitations}

Several limitations of the present study should be noted. Considering the methodology, it is possible that the biases and expectations of the coding team may have influenced the data analysis. The team addressed this threat to validity by conducting a pretest, using predetermined domains, and assessing interrater reliability. Limiting the generalizability of the study, all supervisees were from a single CACREP-accredited counselor training program and almost all were women, although the large proportion of female supervisees in the present study is not uncommon among CACREP-accredited programs. It is also important to note that the number of supervisors represented in the sample was limited.

In addition, the types of feedback may have been affected by the triadic supervision model used and the prompts on the structured review work sheet. Furthermore, the duration of triadic sessions differed among doctoral-level supervisors, from 56 to 148 minutes $(\mathrm{M}=87.57, \mathrm{SD}=$ 21.23), which likely influenced the number of feedback units across categories. It is possible that supervisors' and supervisees' varying theoretical orientations also may have influenced which feedback types were the focus of the session. Although beyond the scope of this study, supervisees did not indicate ratings of satisfaction or helpfulness of the feedback, and we did not delineate whether the feedback was critical or constructive.

Although the Chi-square test indicated a significant relationship between feedback type and supervisee experience level, the effect size was small to medium, suggesting that the practical significance of these results is relatively modest. These results, however, appear consistent with the relatively narrow window of counselor development studied. It is possible that if feedback type had been compared across groups spanning longer time periods, including postgraduation years, the differences may have been more pronounced. Similarly, the smaller number of second- 
semester intern units, in comparison with practicum and first-semester interns, also may have affected the results. Perhaps if more recordings of second-semester interns were included in the analysis, differences in peer feedback between these interns and the other supervision groups would have contributed to the significant Chi-square.

Future Research

Considering the scarcity of existing research on peer feedback in triadic supervision and the exploratory nature of this particular study, there are ample opportunities for future research to add to the body of literature. Future research on feedback during triadic supervision could be useful in developing a framework or model for triadic supervision inclusive of the developmental level of the supervisee and the corresponding feedback preference or match for that level. This type of framework could be beneficial for supervisors wishing to use triadic peer supervision as an intentional intervention with supervisees. Additional research on the model used in this study, with peers watching each other's entire counseling session facilitated by a structured feedback worksheet, or comparisons of several models could illuminate what feedback types (and other outcomes) are achieved by a particular triadic approach. Future researchers may wish to compare the types of feedback to various demographic variables, such as gender, age, and ethnicity, to test for differences. Also, future researchers could focus on feedback given about multicultural considerations in triadic supervision. It may be beneficial to compare feedback across program tracks (i.e., school counseling, clinical mental health, couple and family counseling, college counseling/student development) to determine if there are differences in frequencies and types of feedback among these groups. Furthermore, beyond the type of feedback, the quality of feedback would be important to characterize in future research.

To date, most research on triadic supervision has focused on the experiences of participants (i.e., supervisors and supervisees). Our study provides the first documentation of the content of triadic sessions and suggests that supervisors may need to be intentional about their direction and input during triadic sessions. Thus, our study provides an important step for moving from studies of participants' experiences to a focus on the outcomes of triadic supervision. It would be important for future researchers to examine supervisors' in-session behaviors and their impact on supervisees' behaviors, particular as those supervisee behaviors reflect the supervisors' stated goals for using a triadic approach.

\section{Conclusion}

Peer supervisees across experience levels have the potential to benefit from the vicarious learning opportunities that arise from observing a peer's counseling work. Supervisees have cited these opportunities as a specific advantage of triadic supervision (Borders et al., 2012; Lawson, Hein, \& Stuart, 2009; Stinchfield et al., 2007). Currently, few guidelines related to structured triadic sessions exist, and CACREP has not identified a specific model to follow. Results of our study seem to highlight some specific advantages of triadic supervision related to the facilitation of peer feedback around case conceptualization and performance skills. However, supervisors may need to include structured activities to help supervisees facilitate self-awareness and professional behaviors feedback, because their supervisees may not voluntarily address these areas. Our results add to the growing body of literature and provide additional insights regarding 
the nuances of triadic supervision, although there is much yet to be discovered about this supervision modality.

\section{References}

Agresti, A. (2010). Analysis of ordinal categorical data (2nd ed.). Hoboken, NJ: Wiley.

Bernard, J. M. (1997). The Discrimination Model. In C. E. Watkins Jr. (ed.), Handbook of psychotherapy supervision (pp. 310-327). New York, NY: Wiley.

Bernard, J. M., \& Goodyear, R. K. (2014). Fundamentals of clinical supervision (5th ed.). Upper Saddle River, NJ: Pearson.

Borders, L. D., Welfare, L. E., Greason, P. B., Paladino, D. A., Mobley, A. K., Villalba, J. A., \& Wester, K. L. (2012). Individual and triadic and group: Supervisee and supervisor perceptions of each modality. Counselor Education and Supervision, 51, 281-295.

Cohen, J. (1988). Statistical power analysis for the behavioral sciences (2nd ed.). Hillsdale, NJ: Erlbaum.

Council for Accreditation of Counseling and Related Educational Programs. (2001). CACREP accreditation manual. Alexandria, VA: Author.

Council for Accreditation of Counseling and Related Educational Programs. (2009). 2009 CACREP accreditation manual. Alexandria, VA: Author.

Field, A. P. (2013). Discovering statistics using IBM SPSS statistics: And sex and drugs and rock ' $n$ ' roll (4th ed.). London, England: Sage.

Goodyear, R. K., \& Guzzardo, C. R. (2000). Psychotherapy supervision and training. In S. D. Brown \& R. W. Lent (eds.), Handbook of counseling psychology (3rd ed., pp. 83-108). New York, NY: Wiley.

Hays, D. G., \& Singh, A. A. (2012). Qualitative inquiry in clinical and educational settings. New York, NY: Guilford Press.

Hein, S., \& Lawson, G. (2008). Triadic supervision and its impact on the role of the supervisor: A qualitative examination of supervisors' perspectives. Counselor Education and Supervision, 48, 16-31.

Hein, S. F., \& Lawson, G. (2009). A qualitative examination of supervisors' experiences of the process of triadic supervision. The Clinical Supervisor, 28, 91-108.

Hein, S. F., Lawson, G., \& Rodriguez, C. P. (2011). Supervisee incompatibility and its influence on triadic supervision: An examination of doctoral student supervisors' perspectives. Counselor Education and Supervision, 50, 422-436.

Hein, S. F., Lawson, G., \& Rodriguez, C. P. (2013). Supervisee incompatibility and its influence on supervisee and supervisor outcomes in triadic supervision: An investigation of supervisors' perspectives. The Clinical Supervisor, 32, 260-279.

Insch, G. S., Moore, J. E., \& Murphy, L. D. (1997). Content analysis in leadership research: Examples, procedures, and suggestions for future use. The Leadership Quarterly, 8, 1-25.

Krippendorff, K. (2012). Content analysis: An introduction to its methodology (3rd ed.). Thousand Oaks, CA: Sage.

Landis, J. R., \& Koch, G. G. (1977). The measurement of observer agreement for categorical data. Biometrics, 33, 159-174.

Lawson, G., Hein, S. F., \& Getz, H. (2009). A model for using triadic supervision in counselor preparation programs. Counselor Education and Supervision, 48, 257-270. 
Lawson, G., Hein, S. F., \& Stuart, C. L. (2009). A qualitative investigation of supervisees' experiences of triadic supervision. Journal of Counseling \& Development, 87, 449-457.

Lawson, G., Hein, S. F., \& Stuart, C. L. (2010). Supervisors' experiences of the contributions of the second supervisee in triadic supervision: A qualitative investigation. Journal for Specialists in Group Work, 35, 69-91.

Neuendorf, K. A. (2002). The content analysis guidebook. Thousand Oaks, CA: Sage.

Stemler, S. (2001). An overview of content analysis. Practical Assessment, Research \& Evaluation, 7. Retrieved from http://socialscientist.us/nphs/psychIB/IBReview/Content_analysis_overview.pdf

Stinchfield, T. A., Hill, N. R., \& Kleist, D. M. (2007). The Reflective Model of Triadic Supervision: Defining an emerging modality. Counselor Education and Supervision, 46, $172-183$.

Stinchfield, T. A., Hill, N. R., \& Kleist, D. M. (2010). Counselor trainees' experiences in triadic supervision: A qualitative exploration of transcendent themes. International Journal for the Advancement of Counselling, 32, 225-239.

Stoltenberg, C. D., \& McNeill, B. W. (1997). Clinical supervision from a developmental perspective: Research and practice. In C. E. Watkins Jr. (ed.) Handbook of psychotherapy supervision (pp. 184-202). New York, NY: Wiley. 